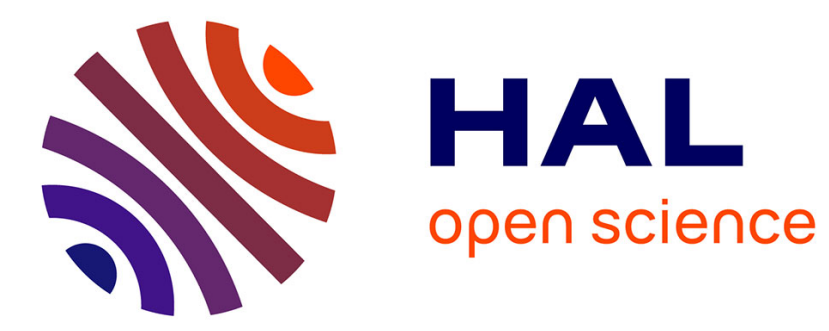

\title{
Quantitative and qualitative analysis of breakfast nutritional composition in French schoolchildren aged 9-11 years
}

E. M. Lepicard, M. Maillot, F. Vieux, M. Viltard, F. Bonnet

\section{- To cite this version:}

E. M. Lepicard, M. Maillot, F. Vieux, M. Viltard, F. Bonnet. Quantitative and qualitative analysis of breakfast nutritional composition in French schoolchildren aged 9-11 years. Journal of Human Nutrition and Dietetics, 2017, 30 (2), pp.151-158. 10.1111/jhn.12412 . hal-01507630

HAL Id: hal-01507630

https://hal-univ-rennes1.archives-ouvertes.fr/hal-01507630

Submitted on 8 Jun 2018

HAL is a multi-disciplinary open access archive for the deposit and dissemination of scientific research documents, whether they are published or not. The documents may come from teaching and research institutions in France or abroad, or from public or private research centers.
L'archive ouverte pluridisciplinaire HAL, est destinée au dépôt et à la diffusion de documents scientifiques de niveau recherche, publiés ou non, émanant des établissements d'enseignement et de recherche français ou étrangers, des laboratoires publics ou privés. 


\section{Quantitative and qualitative analysis of breakfast}

\section{nutritional composition in French schoolchildren 9 to 11 years of age}

Authors: Eve M. Lepicard ${ }^{1}$, Matthieu Maillot ${ }^{2}$, Florent Vieux ${ }^{2}$, Mélanie Viltard ${ }^{1}$, Fabrice Bonnet $^{3}$

\section{Affiliations:}

${ }^{1}$ Institute for European Expertise in Physiology, 21 rue Leblanc, 75015 Paris, France

${ }^{2}$ MS-Nutrition, Boulevard Jean Moulin, Marseille, France

${ }^{3}$ CIC, Inserm U1414, CHU Rennes, F-35000, France; Université de Rennes 1, F-35043

Rennes, France

Corresponding Author: Eve M. Lepicard, Institute for European Expertise in Physiology, 21 Rue Leblanc, 75015 Paris, France. Tel: +33 1406001 57. E-mail: evelepicard@ieepworld.fr. 


\section{Abstract}

This study aimed to analyze the nutritional quality of children breakfast using data collected during a cross-sectional observational study on the prevalence of urinary osmolality in 529 French children aged 9 to 11 years. Total nutrient intake, mean adequacy ratio (MAR), energy density (ED) and solid energy density were calculated from individual breakfast food and fluid nutritional composition. To identify the main qualitative breakfast patterns, each breakfast item was categorized into 15 solid and liquid food categories and a principal component followed by a cluster analysis were performed.Only 9.8\% included skipped breakfast. Breakfast provided, on average, $22.9 \%$ of the recommended daily energy intake and $24.7 \%$ of the mean adequacy ratio of 23 key nutrients. Four breakfast patterns were identified: “sweets breakfast” (40.0\% of children), "traditional French breakfast” (27.2\%), “ready-to-eat cereal (RTEC) + milk” (18.1\%), and “dairy and juice breakfast” (9.5\%).

Nutritionally, the "RTEC + milk" pattern was the most advantageous. Flavoured milk was the most frequently consumed food (50.5\%) and the major component of the "traditional French breakfast”. While breakfast provided a substantial contribution to a range of nutrients, opportunity for improvement, particularly to less nutrient breakfast patterns, should not be overlooked..

Key words: nutrition, breakfast, energy, schoolchildren, France 


\section{Introduction}

Eating breakfast is recommended and considered the most important meal of the day because it is associated with good health behaviours, reduced risk of chronic diseases, and improved cognitive and school performance (Giovannini et al., 2010). In addition, eating breakfast, especially a breakfast rich in proteins and low in glycaemic index carbohydrates, correlates with a normal body mass index (BMI), whereas skipping breakfast is frequently associated with overweight and obesity (Szajewska and Ruszczynski, 2010, De La Hunty et al., 2013).

Breakfast composition varies across the world, but precisely defining how much energy it should provide is difficult, and national recommendations vary. The US Department of Agriculture established four definitions of breakfast (Sackin, 2005). The simplest definition is any food or beverage except water. The three other definitions constitute "substantial breakfasts” and include foods from at least two of the five major food groups (breads/grains, fruits, vegetables, meat/meat alternate, and milk). They provide, respectively, $>10 \%, 15 \%$, and $25 \%$ of the Recommended Dietary Allowances for energy (calories) and one-fourth of the Recommended Daily Allowance of nutrients based on the latest Dietary Guidelines for Americans (U.S. Department of Agriculture and U.S. Department of Health and Human Services, 2010).

France does not appear to have a specific recommendation on the percentage of energy provided by breakfast, although current recommendations are to eat at least one food containing cereals, one fruit or freshly squeezed juice or juice with no added sugar, and one dairy product (Agence Française De Sécurité Sanitaire Des Aliments, 2004). Quantities in grams or millilitres for each of these components are not provided in the recommendations but can be found in the revised version of the Recommandation Nutrition of the Groupe 
d'étude des Marchés de Restauration Collective et Nutrition GEM-RCN (Guide on Nutrition Recommendations for Mass Catering) (Groupe D'etude Des Marches De Restauration Collective Et Nutrition (Gem-Rcn), 2013) published by the French Ministry of Economic Affairs and Finance. Rates of breakfast consumption in French children 3 to 12 years of age were 91\% in 2003 and 87\% in 2010 (Hebel, 2013), but little detailed information is available about breakfast habits, and the most recent nutritional studies are more than a decade old (Billon et al., 2002, Preziosi et al., 1999).

In the current study, we analysed breakfast composition in France using data extracted from a recent survey examining breakfast water intake by schoolchildren 9-11 years of age (Bonnet et al., 2012). Our objectives were, first, to assess energy and nutritional quality of breakfast and, second, to identify the main breakfast patterns, that is, how foods and drinks were associated in the children's breakfasts. We also evaluated whether the children were meeting French national recommendations.

\section{Methods}

\section{Study design and dietary record}

The current analysis was based on data collected as part of a prospective, cross-sectional study carried out in Rennes, France between 2010 and 2011 (Bonnet et al., 2012). The protocol for the study was approved by AFSSAPS (French Health Products Safety Agency) and the Ethics Committee of Rennes Ouest V, France, and the study was conducted according to the guidelines laid down in the Declaration of Helsinki. Written informed consent was obtained from both parents and children. 
Briefly, in the Rennes study, children 9 to 11 years of age were recruited on a voluntary basis through 14 primary schools from the city of Rennes and vicinity. This area includes urban as well as rural populations from various socioeconomic strata. All children were given a study pack to take home. The pack contained a study information document, a parent and child consent form, a questionnaire covering demographic information, height and weight, and breakfast composition. Breakfast was defined as the first meal of the day consumed in the morning. Breakfast intake data were reported for one day. To address potential difference between weekday and week-end breakfast composition, clinical investigators recommendation was to fill the questionnaire on a weekday only. Children were instructed to follow their usual morning routine and, if breakfast was eaten, to record consumption in a diary, including time of consumption, product brand name, cooking method, and portion size. Children returned study materials, including the urine sample, to the teachers on designated days. Children were included if both parents had signed the informed consent and if they fulfilled the inclusion criteria, which included a usual intake of at least two main meals per day. Children were excluded if they currently or previously had a metabolic or digestive disease (with the exception of appendectomy) or renal disease (renal insufficiency etc.), if they had fever, or if they were prescribed a local or systemic treatment likely to interfere with evaluation of the study parameters, including hydration state in particular (diuretic treatment or treatment interfering with metabolism and eating behavior).

Overweight, obesity, and underweight were determined from the BMI and age according to the 2012 International Obesity Task Force cut-off values (Cole and Lobstein, 2012). 


\section{Energy and nutrient intakes}

Dietary intake was determined using information recorded in diaries by children and/or parents. Breakfast skippers included children having no food and no fluid and children who took their first meal at lunch time. Having only a drink was considered as breakfast. All food and drink consumed at breakfast, or the last meal of the previous day in case of children not consuming breakfast, were recorded, including brand name and portion size (household measures or package weight) (Bonnet et al., 2012). Dietary data were entered in BILNUT 7.5 nutrition software (Nutrisoft, Mesa, AZ), which converts the amount of food eaten into individual energy, macronutrients, and micronutrients and assigns consumed foods to food groups and subgroups. For children consuming several foods, if the nutritional content of one or more foods was missing, no intake was assumed. If all foods were missing, the child's data were considered missing and therefore not included in the calculations. Foods were categorized as described previously (Alexy et al., 2010) and included the following food and drink categories: bread, ready-to-eat cereals (RTEC), sweets (biscuits, pastries, bakery goods, chocolate, jam, candy, honey, sugar, and syrup), fat/oil, fruits/vegetables, meat/fish/egg, dairy,

water, milk, juices, flavoured milk, coffee, tea, soda/soft drink/sport drink, and miscellaneous. The combination of milk and sweetened cocoa powder were considered as a single food (flavoured milk). For each individual, the total amount of food consumed, total energy intake, energy intake from liquids, and energy intake from solid foods were calculated.

\section{Nutritional quality of breakfast}

Energy intake from breakfast was compared to the daily recommended energy intake derived from the joint FAO/WHO/UNU Expert Consultation of 2001 (Joint Fao/Who/Unu Expert Consultation, 2001). Nutritional quality of breakfasts was estimated using the energy density 
(kcal/100 g) and the mean adequacy ratio (MAR). Energy density was the ratio between energy intake (kcal) and amount of foods (g) and was calculated first for total foods and then for solid foods only. The MAR was calculated as the mean percentage of daily recommended intakes for 23 key nutrients (Maillot et al., 2007, Vieux et al., 2013) in relation to the French recommendations (Martin, 2001). These 23 nutrients included protein, fibre, retinol, thiamine, riboflavin, niacin, vitamin B-6, folates, vitamin B-12, ascorbic acid, vitamin E, vitamin D, calcium, potassium, iron, magnesium, zinc, copper, iodine, docosahexaenoic acid (DHA), linoleic acid, linolenic acid, and selenium. The ratio for each nutrient was truncated at 100 so that a high intake of one nutrient could not compensate for the low intake of others.

\section{Dietary patterns}

Based on the amounts consumed of the 13 food categories, a principal component analysis including a Varimax rotation was used to extract latent variables explaining most variability in individual dietary habits. Only three subjects were considered as outliers and were removed from the PCA in order to to obtain homogeneous and robust dietary patterns. The first four latent variables were retained and used to run a hierarchical ascendant classification based on Ward criteria.

\section{Statistical analysis}

Averages of energy intake (total, solid, and liquid) and amount of foods (total, solid, and liquid), energy density (total and solid), MAR, and nutrients expressed in per cent of recommendations were calculated in the whole sample and by sex. Differences by sex were compared using a general linear model. Additional calculations included the percentage of breakfast skippers, the number of consumers, and the average amount consumed (g) by food category. The four most frequent breakfast patterns were determined by principal component 
analysis. P-values were calculated using a general linear model with food group as the dependant variable and the dietary pattern variable as the independent variable. A pair-wise statistical t-test was performed to compare the MAR between dietary patterns. Consumption of the different food categories was compared between breakfast patterns using a general linear model with food group as the dependant variable and the dietary pattern variable as the independent variable.

Statistical analysis was performed using SAS for Windows, version 9.4 (SAS Institute, Cary, NC). Missing data were not replaced and no imputation was made. A p-value below 0.05 was considered to indicate statistical significance.

\section{Results}

\section{Subjects}

The analysis included 529 children from 9 to 11 years of age. Just over half ( $n=269 ; 50.8 \%$ ) were boys. Using International Obesity Task Force cut-offs (Cole, 2012 A INTEGRER), according to BMI, 70.1\% ( $\mathrm{n}=371)$ had a normal weight, 5.9\% $(\mathrm{n}=31)$ were overweight, $12.9 \%$ ( $n=68$ ) were underweight, and none were considered obese. BMI could not be calculated for 59 subjects because of missing height and/or weight data. Mean BMI was $16.7 \pm 1.9$ in boys and $16.2 \pm 2.0 \mathrm{~kg} / \mathrm{m}^{2}$ in girls. The mean body weight, $31.6 \mathrm{~kg}$, was slightly

higher than the values previously observed in a French population (Rolland-Cachera MF, Cole TJ, Sempe M, Tichet J, Rossignol C, Charraud A: Body mass Index variations: centiles from birth to 87 years. Eur J Clin Nutr 1991; 45: 13-21. REF A INTEGRER) but prevalence of both obesity and excessive weight observed in our study was lower than that reported in 
Europe for children of the same age (De Henauw et al, Obes Rev. 2015 Dec;16 Suppl 2:16-

29; Pigeot et al, International Journal of Obesity (2009) 33, 1103-1110 REF A INTEGRER).

\section{Breakfast intake}

Overall, 9.8\% of the children ( $\mathrm{n}=52)$ skipped breakfast. The frequency of breakfast skipping increased with age (8.2\% at 9 years of age, $11.4 \%$ at 10 years of age, and $16.7 \%$ at 11 years of age).

For breakfast consumers ( $n=477)$, the mean quantity of food consumed at breakfast was $442 \pm$ $167 \mathrm{~g}$ (Table 1) and the mean energy intake was $445 \pm 159 \mathrm{kcal}$ (Table 1). Apart from the chocolate milk, other drinks consumed in big quantities by the children - mainly water and tea- provide no calorie at all. Thus the contribution of liquids to the total breakfast quantity is far greater than the contribution of liquids to the breakfast total energy: about three- quarters of the total quantity ingested was provided by drinks, whereas breakfast energy was mainly provided by food, reflecting the fact that children consumed drinks that had low calorie contents and that they consumed energy-rich foods. Total energy intake did not significantly differ between girls and boys (433 \pm 151 vs. $457 \pm 165$ kcal; p=0.0995). Energy intake from foods and drinks also did not differ between girls and boys.

Sweets were the most frequently consumed food item, consumed by $67.7 \%$ of the subjects, and they accounted for $40.1 \pm 25.3 \%$ of the total energy consumed for those who ate them (Table 2). Fat (mainly butter) (41.5\%) and bread (46.8\%) were also frequently consumed. Flavoured milk accounted for the highest number of grams of food consumed and was consumed by nearly half (48.9\%) of the children. RTECs, not a traditional breakfast food in France, were consumed by $28.1 \%$ of children. 


\section{Nutrient intake at breakfast}

Nutritional quality as assessed by MAR was similar for boys (25.4 \pm 8.9\%) and girls (24.1 \pm 9.9\%), and overall, the MAR for breakfast was 24.7\% (Table 3). Energy density from solid foods and total energy density were also similar between boys and girls. On average, breakfast provided $22.9 \%$ of the daily energy requirement according to international recommendations (Joint Fao/Who/Unu Expert Consultation, 2001) (Table 4). It also provided $49.2 \%$ of recommended protein $(0.9 \mathrm{~g} / \mathrm{kg}$, the main contributors to protein intake being flavored milk (33\%), sweets (20\%), and milk (15\%) categories), $18.5 \%$ of fat, $28.3 \%$ of carbohydrates, and $15.9 \%$ of fibre. Breakfast contributed more than half the daily requirement of vitamin B2 (riboflavin; 51.2\%) and more than $40 \%$ of the daily requirements for protein, phosphorus, pantothenic acid, and vitamin B12. However, breakfast provided less than $10 \%$ of linoleic acid, alpha-linolenic acid, DHA, selenium, and vitamin D.

The contribution of breakfast to the daily energy requirement was significantly different between boys and girls ( $21.74 \pm 8.08 \%$ vs. $24.17 \pm 9.49 \%$; $p=0.0026)$ (Table 4). Breakfast contribution to daily requirements also differed between boys and girls for energy from solids ( $14.85 \pm 6.97 \%$ vs. $16.28 \pm 8.08 \%$; $p=0.0374)$, energy from liquids $(6.89 \pm 3.79 \%$ vs. $7.89 \pm$ 4.93\%; $\mathrm{p}=0.0134)$, fat (17.48 $\pm 9.91 \%$ vs. $19.51 \pm 10.63 \%$; $\mathrm{p}=0.0313)$, carbohydrates $(26.89 \pm$ 9.42\% vs. $29.83 \pm 12.24 \%$; $\mathrm{p}=0.0033)$, saturated fatty acids $(28.71 \pm 17.45 \%$ vs. $34.47 \pm$ 21.50\% $\mathrm{p}=0.0014)$, and sodium $(14.50 \pm 8.12 \%$ vs. $16.27 \pm 9.86 \% ; \mathrm{p}=0.0322)$.

The main contributor to total energy at breakfast was flavoured milk, followed by sweets and RTEC, milk, and dairy (Table 2). The highest MAR was provided by flavoured milk (15.5\%), RTEC (11.3\%), and milk (11.2\%). Although sweets contributed substantially to energy intake, they contributed less to nutrient intake (MAR $=5.8 \%)$. Fruits and vegetables 
accounted for $8 \%$ of recommended values and $18 \%$ of total energy. After adjustment for energy, the food categories providing the most nutrients were, in decreasing order, RTEC, milk, flavoured milk, and fruits.

\section{Dietary patterns}

Four main dietary patterns were identified: “RTEC + milk breakfast” (18.1\%), which included mainly RTEC, milk, and juice; “sweets breakfast” (40.0\%), which included mainly flavoured (i.e. chocolate) milk and sweets, especially brioche and chocolate spread, plus water or juice; “traditional French breakfast” (27.2\%), which included mainly flavoured milk, bread, fat (especially butter), and juice; and “dairy and juice breakfast” (9.5\%), which included mainly dairy (especially whole milk yogurt or yogurt drink), sweets, and tea or juice (Table 5).

On average, energy intake was slightly higher for the "traditional French breakfast” (496 kcal) and the "sweets breakfast" (440 kcal) than for the other two breakfast patterns (approximately $400 \mathrm{kcal}$ each). When adjusted for total energy intake at breakfast, the mean MAR was higher for the "RTEC + milk breakfast" (30.2\%), followed by the "sweets breakfast" (24.6\%) and the “traditional French breakfast” (22.6\%) and lower for the “dairy and juice breakfast” (18.0\%). Total energy density was lower for the "RTEC + milk breakfast” but not significantly different from the “dairy and juice breakfast”.

\section{Discussion}

The study provided a snapshot of a single breakfast in over 500 schoolchildren 9-11 years old in France. Data were collected as part of a previous study examining fluid intake at breakfast (Bonnet et al., 2012). The sample included a similar number of girls and boys, and the majority of children were 9 to 10 years of age because they were recruited in primary schools. 
Only $10 \%$ of the children skipped breakfast, which is less than in most developed countries (Alexy et al., 2010, Vanelli et al., 2005, Deshmukh-Taskar et al., 2010). However, we observed a trend of declining breakfast with age. Skipping breakfast is more and more observed in many developed countries, with 10 to 30\% children and adolescents having lunch or even dinner as the first meal of the day (for review, see Rampersaud, G. C., Pereira, M. A., Girard, B. L., Adams, J., \& Metzl, J. D. (2005). Breakfast habits, nutritional status, body weight, and academic performance in children and adolescents. Journal of the American Dietetic Association, 105, 743-760; quiz 761-762. doi:10.1016/j.jada.2005.02.007).”

Almost half of the children (48.6\%) consumed a breakfast that included cereals, dairy, fruit/fruit juice in accordance with the recommendations of France’s Programme National Nutrition Santé (National Health Nutrition Programme). All children consumed at least one beverage. Most breakfast consumers (83\%) consumed milk, flavoured milk, a dairy product, or a combination of them. As a beverage, flavoured milk has a lower energy density than solid foods. It contributes to several nutrient recommendations without providing many calories. More than half of breakfast consumers (58\%) consumed fruit juice, and 11\% consumed fruits. Bread was consumed by $47 \%$ of breakfast consumers and RTEC by $28 \%$. The amount of RTEC consumed (30.45 g) is very close to the portion recommended (30g). This rather high percentage is interesting, because RTEC are not traditionally consumed in France, and are not, as such, a recommendation of the PNNS..

The study showed that breakfast provided, on average, $22.9 \%$ of the recommended daily energy intake. This is slightly higher than in the Stanislas family study (Billon et al., 2002) but similar to the 15-25\% medium interval observed in France in 1999 (Preziosi et al., 1999). Flavoured milk was the main contributor to energy intake, followed by sweets, RTEC, milk, 
dairy, bread, fat/oil, fruits/vegetables, and juice, consistent with them being amongst the most consumed breakfast items in terms of grams and energy

The study also showed a MAR of breakfast of $24.7 \%$, indicating that, on average, breakfast provided a substantial amount of the daily recommended intakes for 23 key nutrients. When adjusted for energy, the foods contributing most to total nutrient intake were, in decreasing order, RTEC, milk, flavoured milk, and fruits. Average intake of protein, carbohydrates, most minerals (e.g. calcium, magnesium, phosphorus, and potassium), and vitamins (e.g. vitamin B2, and pantothenic acid) appeared to be sufficient. Intake was below national recommendations for vitamin E, vitamin B12, vitamin D, eicosapentaenoic acid/DHA, essential fatty acids, copper, zinc, selenium, and fibre, whereas intake of saturated fatty acids was in excess of recommendations. Because other meals may not provide sufficient nutrients to reach adequate intake, substituting foods currently consumed at breakfast with others of nutritional content may be necessary. For instance, consuming bakery products or RTEC containing whole grains or whole wheat flour may help provide adequate fibre.

By total grams consumed, the largest contributor to breakfast was flavoured milk, which was consumed by just over half (50.5\%) of the children. For these children, milk provided $43 \%$ of their energy intake. In addition, the highest MAR was provided by flavoured milk (15.5\%) and the third highest was from plain milk (11.2\%). This agrees with the French Individual National Food Consumption Survey 2 in 2005-2007, which found that, in children, milk is a strong contributor of several nutrients, especially calcium, iodine, phosphorus, potassium, zinc, retinol, and vitamins B2, B12, B5, and D (Coudray, 2011).

We identified two dominant breakfast patterns: "sweets breakfast”, eaten by $45 \%$ of children and included mainly flavoured (i.e. chocolate) milk, fruit juice, and a Danish, biscuit, or 
pastry; and "traditional French breakfast”, eaten by 27\% of children and included bread, butter or margarine, and flavoured milk. The "RTEC + milk” breakfast pattern, which consisted of RTEC, milk, and fruit juice, was the most nutrient-dense but was eaten by only $18 \%$ of children. This suggests that although the traditional French breakfast (bread and butter) is still common, new patterns are emerging, including consumption of RTEC.

Nutritionally, the "RTEC + milk" pattern was the most advantageous pattern because it was low in total fat, saturated fatty acids, and cholesterol and was rich in fluids, vitamins B, vitamin C, calcium, and iron. The "dairy and juice breakfast” did not provide sufficient calcium, protein, or water. This may be due to the fact that, in France, by portion, dairy products have lower contents of these nutrients than milk.

This study has some limitations: fluid and food intake were estimated from a self-reported questionnaire, which could have led to inaccuracies in portion size as well as height and weight. Second, the classification we adopted was aimed essentially at defining the various breakfast patterns. To get even more information on the nutritional quality of foods eaten at breakfast, a classification with further groups would be useful. For instance, the sweets category could be subdivided into pastries (bringing complex and simple carbohydrates, as well as fats), sugar/jam (bringing simple carbohydrates) and chocolate spreads (bringing simple carbohydrates and fats).

This study is the first report on breakfast composition in French children. Based on a large sample size, it provides insights about the breakfast habits in school children and opens new perspectives in terms of nutritional education and public policies. Based on our results, some recommendations can be made to optimize the breakfast composition and the formula of breakfast food products and drinks. For instance, the breakfast composition of French children 
included all food and drink categories (one portion of cereal, one dairy product, and one drink) recommended in the PNNS except the fruit/100\% fruit juice category. In all dietary patterns identified in our study, consumption of fresh fruit was low. Children preferred fruit juices as observed in the "RTEC + milk" and "Dairy \& juice” patterns. However, this trend was not observed in all dietary patterns: fruit juice consumption was low in the "Sweets" and “traditional French” patterns. In addition, insufficient intake of some micronutrients including copper, zinc, selenium and vitamin B12 and vitamin D as well as EPA/DHA have been observed. Fortification of food and drink products may provide a solution to compensate these deficiencies. Fibers intake is also below recommendations. This could be improved by encouraging consumption of RTEC (with an adequate amount of salt and sugar) or breakfast bakery products containing cereals and/or whole flour. Finally, consumption of margarine with omega 6/omega 3/ vitamin E and partially skimmed milk could be encouraged to reduce intake of saturated fatty acids.

\section{Conclusions}

This study on breakfast consumption by French schoolchildren produced globally encouraging results: only $10 \%$ of children skipped breakfast, breakfast composition and energy intake were close to national recommendations, and breakfast provided a substantial amount of the daily recommended intake for 23 key nutrients. To optimize further the children breakfast composition, it is recommended to increase intake of some micronutrients (copper, zinc, selenium, vitamin B12, vitamin D, EPA/DHA) possibly via food and drink fortification as well as fiber intakes by encouraging the consumption of fruits and whole grain products. 


\section{Acknowledgments}

The authors thank Dr Yves M. Darmon for his critical reading of the manuscript. Medical writing was provided by Dr. Phillip S. Leventhal (4Clinics, Paris, France). This study was funded by the Institute for European Expertise in Physiology (Paris, France) and Nestlé Dairy (Vevey, Switzerland).

\section{Declaration of interest}

The work of Eve Lepicard and Mélanie Viltard was paid for by Nestlé Dairy, and the work of Matthieu Maillot and Florent Vieux was paid for by IEEP. Fabrice Bonnet declares no conflicts of interest.

\section{References}

Agence Française De Sécurité Sanitaire Des Aliments 2004. La santé vient en mangeant et en bougeant [Health comes from eating and moving]. In: Santé, I. N. D. P. E. D. E. P. L. (ed.). Maisons-Alfort, France.

Alexy, U., Wicher, M. \& Kersting, M. (2010). Breakfast trends in children and adolescents: frequency and quality. Public Health Nutr 13: 1795-802.

Billon, S., Lluch, A., Gueguen, R., Berthier, A. M., Siest, G. \& Herbeth, B. (2002). Family resemblance in breakfast energy intake: the Stanislas Family Study. Eur J Clin Nutr 56: 1011-9.

Bonnet, F., Lepicard, E. M., Cathrin, L., Letellier, C., Constant, F., Hawili, N. \& Friedlander, G. (2012). French children start their school day with a hydration deficit. Ann Nutr Metab 60: 257-63. 
Cole, T. J. \& Lobstein, T. (2012). Extended international (IOTF) body mass index cut-offs for thinness, overweight and obesity. Pediatr Obes 7: 284-94.

Coudray, B. (2011). The contribution of dairy products to micronutrient intakes in France. J Am Coll Nutr 30: 410S-4S.

De La Hunty, A., Gibson, S. \& Ashwell, M. (2013). Does regular breakfast cereal consumption help children and adolescents stay slimmer? A systematic review and meta-analysis. Obes Facts 6: 70-85.

Deshmukh-Taskar, P. R., Nicklas, T. A., O'neil, C. E., Keast, D. R., Radcliffe, J. D. \& Cho, S. (2010). The relationship of breakfast skipping and type of breakfast consumption with nutrient intake and weight status in children and adolescents: the National Health and Nutrition Examination Survey 1999-2006. J Am Diet Assoc 110: 869-78.

Giovannini, M., Agostoni, C. \& Shamir, R. (2010). Symposium overview: Do we all eat breakfast and is it important? Crit Rev Food Sci Nutr 50: 97-9.

Groupe D'etude Des Marches De Restauration Collective Et Nutrition (Gem-Rcn). (2013). RECOMMANDATION NUTRITION. Paris: Ministère de Finances et des Comptes publics.

Hebel, P. (2013). Le petit-déjeuner en perte de vitesse. Consommation et Modes de Vie 259: $1-4$.

Joint Fao/Who/Unu Expert Consultation 2001. Human Energy Requirements. Report of a Joint FAO/WHO/UNU Expert Consultation. FAO Food and Nutrition Techical Report Series. Rome, Italy: Food and Agricultural Organization of the United Nations. 
Maillot, M., Darmon, N., Vieux, F. \& Drewnowski, A. (2007). Low energy density and high nutritional quality are each associated with higher diet costs in French adults. Am J Clin Nutr 86: 690-6.

Martin, A. (2001). Apports nutritionnels conseillés pour la population française. Paris: Editions Tec \& Doc.

Preziosi, P., Galan, P., Deheeger, M., Yacoub, N., Drewnowski, A. \& Hercberg, S. (1999). Breakfast type, daily nutrient intakes and vitamin and mineral status of French children, adolescents, and adults. J Am Coll Nutr 18: 171-8.

Sackin, A. (2005). Breakfast for all and all for breakfast? School and Food Service Nutrition November: 32-38.

Szajewska, H. \& Ruszczynski, M. (2010). Systematic review demonstrating that breakfast consumption influences body weight outcomes in children and adolescents in Europe. Crit Rev Food Sci Nutr 50: 113-9.

U.S. Department of Agriculture and U.S. Department of Health and Human Services. (2010). Dietary Guidelines for Americans, 2010. Washington, DC: U.S. Government Printing Office.

Vanelli, M., Iovane, B., Bernardini, A., Chiari, G., Errico, M. K., Gelmetti, C., Corchia, M., Ruggerini, A., Volta, E. \& Rossetti, S. (2005). Breakfast habits of 1,202 northern Italian children admitted to a summer sport school. Breakfast skipping is associated with overweight and obesity. Acta Biomed 76: 79-85.

Vieux, F., Soler, L. G., Touazi, D. \& Darmon, N. (2013). High nutritional quality is not associated with low greenhouse gas emissions in self-selected diets of French adults. Am J Clin Nutr 97: 569-83. 
Table 1. Total amounts and energy consumed at breakfast

\begin{tabular}{|c|c|c|c|c|}
\hline \multirow{2}{*}{ Category } & \multicolumn{3}{|c|}{ Mean amount \pm SD } & \multirow{2}{*}{$\begin{array}{c}\text { P-value } \\
\text { (girls vs. boys) }\end{array}$} \\
\hline & Overall & Girls & Boys & \\
\hline Total quantity (g) & $442 \pm 167$ & $440 \pm 164$ & $443 \pm 171$ & 0.8479 \\
\hline Quantity from drinks (g) & $341 \pm 169$ & $342 \pm 170$ & $341 \pm 168$ & 0.9256 \\
\hline Energy (kcal) & $445 \pm 159$ & $433 \pm 151$ & $457 \pm 165$ & 0.0995 \\
\hline Energy from foods (kcal) & $303 \pm 141$ & $293 \pm 134$ & $312 \pm 144$ & 0.1389 \\
\hline
\end{tabular}

$\mathrm{SD}$, standard deviation. 
Table 2. Consumption by food category for breakfast consumers $(\mathrm{N}=477)$

Mean

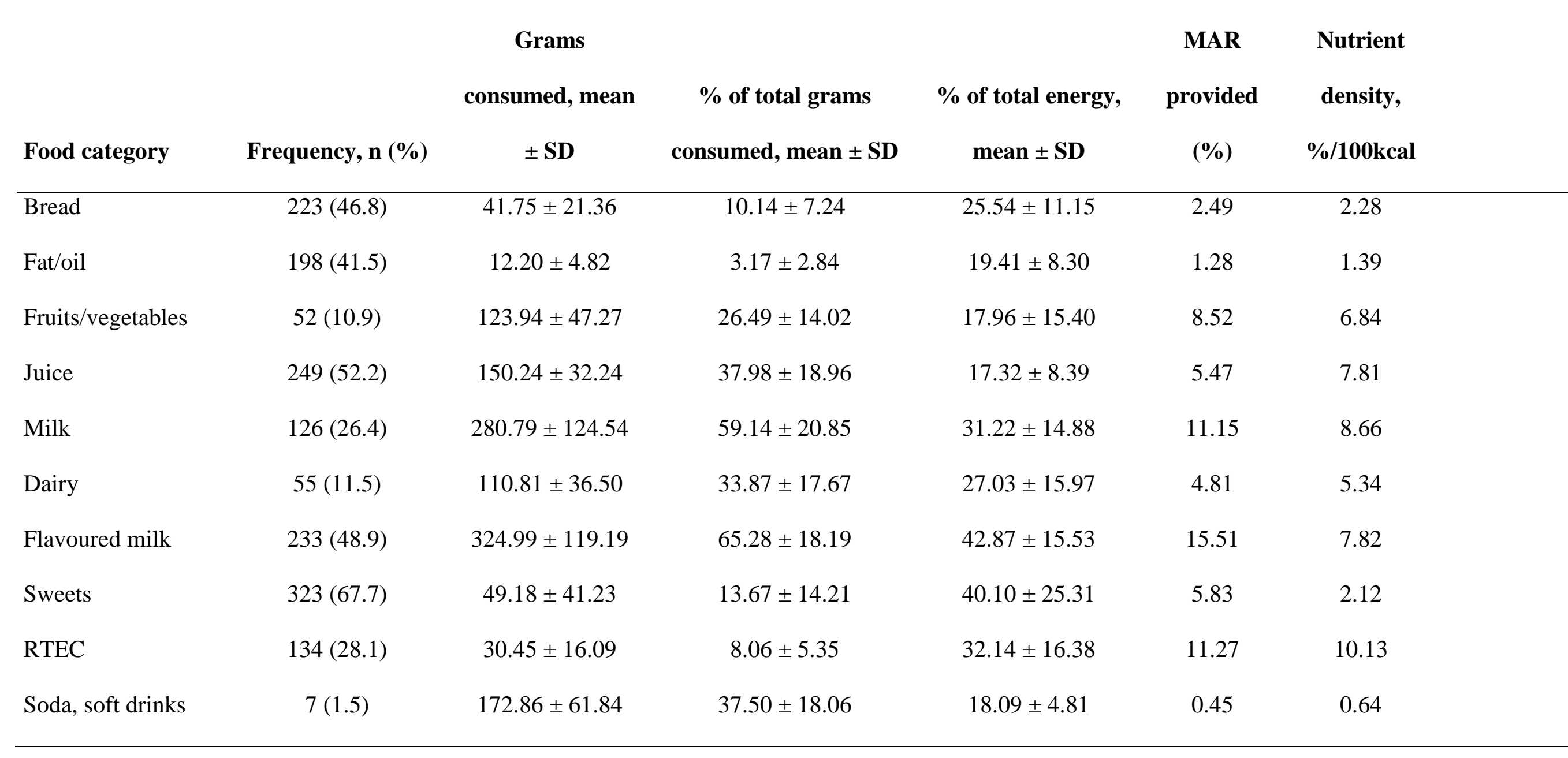




\begin{tabular}{lcccccc}
\hline Tea & $22(4.61)$ & $246.82 \pm 92.14$ & $47.11 \pm 20.34$ & $0.13 \pm 0.07$ & 0.00 & 0 \\
Water & $80(16.8)$ & $135.63 \pm 25.65$ & $32.27 \pm 14.79$ & $0.00 \pm 0.00$ & 0.00 & - \\
Meat/fish/egg & $4(0.8)$ & $72.50 \pm 55.60$ & $15.26 \pm 11.18$ & $19.14 \pm 14.04$ & - \\
Miscellaneous & $1(0.2)$ & 100 & 16.75 & 43.53 & - \\
\hline
\end{tabular}


Table 3. Main breakfast patterns and compositions in breakfast consumers $(n=474)$

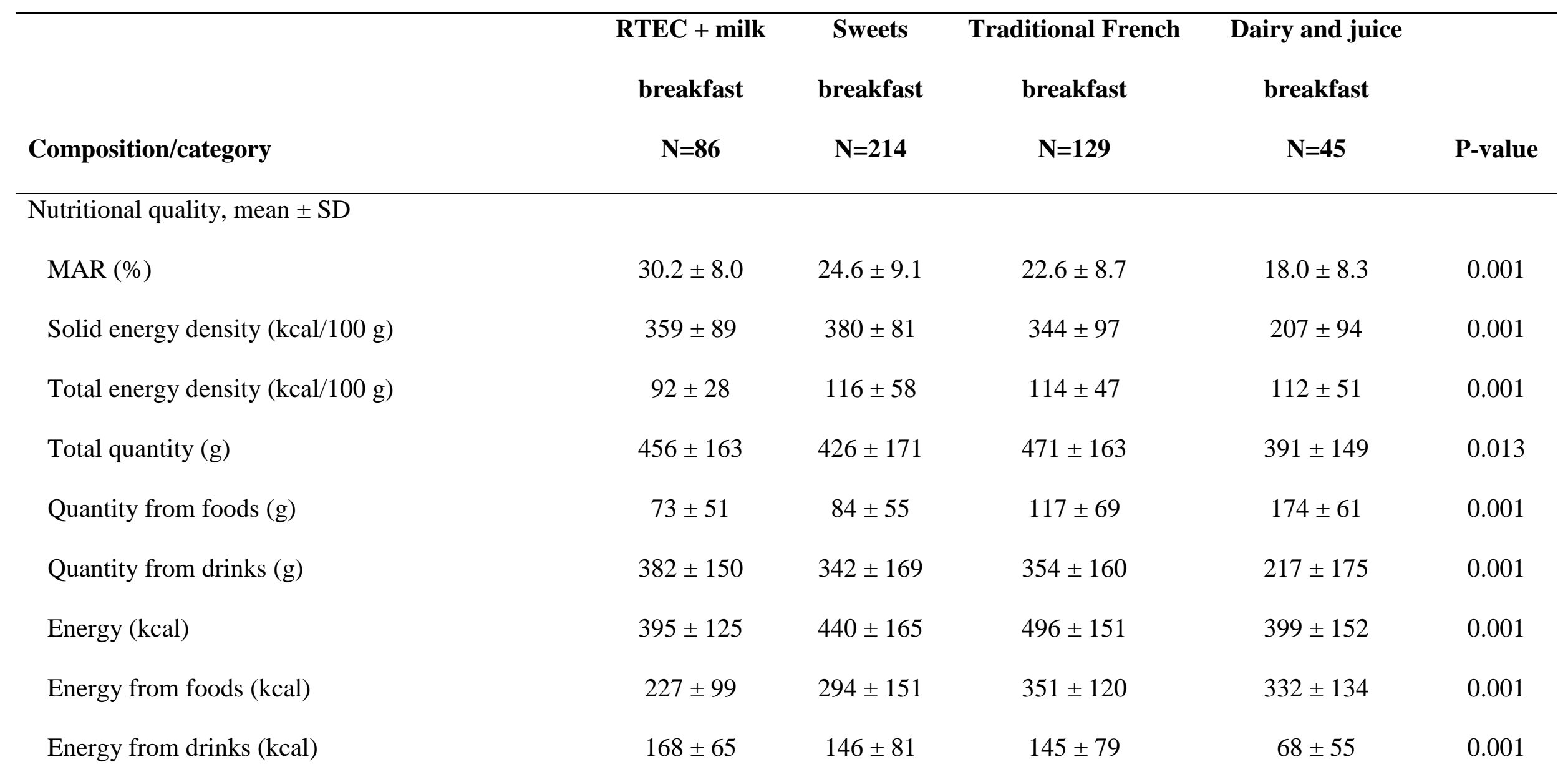

Grams consumed by food group, mean \pm SD 


\begin{tabular}{|c|c|c|c|c|c|}
\hline Bread & $11 \pm 18$ & $7 \pm 13$ & $49 \pm 24$ & $13 \pm 21$ & 0.001 \\
\hline Fats & $1.9 \pm 4.4$ & $5.5 \pm 4.9$ & $12.2 \pm 6.0$ & $3.2 \pm 5.3$ & 0.001 \\
\hline Fruits and vegetables & $13 \pm 40$ & $10 \pm 37$ & $21 \pm 52$ & $12 \pm 34$ & 0.142 \\
\hline Juice & $93 \pm 76$ & $77 \pm 76$ & $63 \pm 82$ & $99 \pm 77$ & 0.011 \\
\hline Milk & $256 \pm 163$ & $42 \pm 110$ & $14 \pm 52$ & $39 \pm 82$ & 0.001 \\
\hline Dairy & $5.3 \pm 22.8$ & $0.4 \pm 3.5$ & $8.5 \pm 31.0$ & $98.4 \pm 54.2$ & 0.001 \\
\hline Flavoured milk & $8 \pm 34$ & $203 \pm 184$ & $240 \pm 181$ & $11 \pm 40$ & 0.001 \\
\hline Sweets & $12 \pm 19$ & $51 \pm 48$ & $16 \pm 22$ & $41 \pm 38$ & 0.001 \\
\hline RTEC & $29.2 \pm 13.6$ & $4.6 \pm 10.5$ & $1.71 \pm 6.1$ & $3.3 \pm 8.0$ & 0.001 \\
\hline Soda, soft drinks & $6.5 \pm 29.9$ & $0.7 \pm 10.3$ & $3.9 \pm 31.6$ & $0.0 \pm 0.0$ & 0.146 \\
\hline Tea & $1.4 \pm 12.9$ & $5.3 \pm 36.9$ & $18.1 \pm 69.4$ & $40.9 \pm 103.7$ & 0.001 \\
\hline Water & $365 \pm 143$ & $330 \pm 151$ & $363 \pm 141$ & $307 \pm 136$ & 0.033 \\
\hline Meats, fish, eggs & $0.0 \pm 0.0$ & $0.0 \pm 0.0$ & $0.0 \pm 0.0$ & $3.1 \pm 12.6$ & NC \\
\hline
\end{tabular}

The four most frequent breakfast patterns were determined by principal component analysis. Three subjects considered as outliers were removed from the principal component analysis to obtain homogeneous and robust dietary patterns. P-values were calculated using a general linear model 
with food group as the dependant variable and the dietary pattern variable as the independent variable. NC, P-value could not be calculated; SD,

standard deviation. 
Supplementary table 1. MAR and energy density for breakfast consumers

\begin{tabular}{lccccccc}
\hline & & Overall & & Girls & & Boys & P-value (girls \\
Value & N & Mean \pm SD & N & Mean \pm SD & N & Mean \pm SD & vs. boys) \\
\hline MAR (\%) & 424 & $24.7 \pm 9.4$ & 213 & $24.1 \pm 9.9$ & 211 & $25.4 \pm 8.9$ & 0.1503 \\
Energy density from solid foods (kcal/100 g) & 477 & $350 \pm 100$ & 230 & $347 \pm 98$ & 247 & $352 \pm 102$ & 0.6216 \\
Total energy density (kcal/100 g) & 477 & $111 \pm 51$ & 230 & $109 \pm 57$ & 247 & $112 \pm 45$ \\
\hline
\end{tabular}

P-values for girls vs. boys were calculated using a general linear model. SD, standard deviation. 
Supplementary table 2. Intake of nutrients as a percentage of the daily recommended values for breakfast consumers

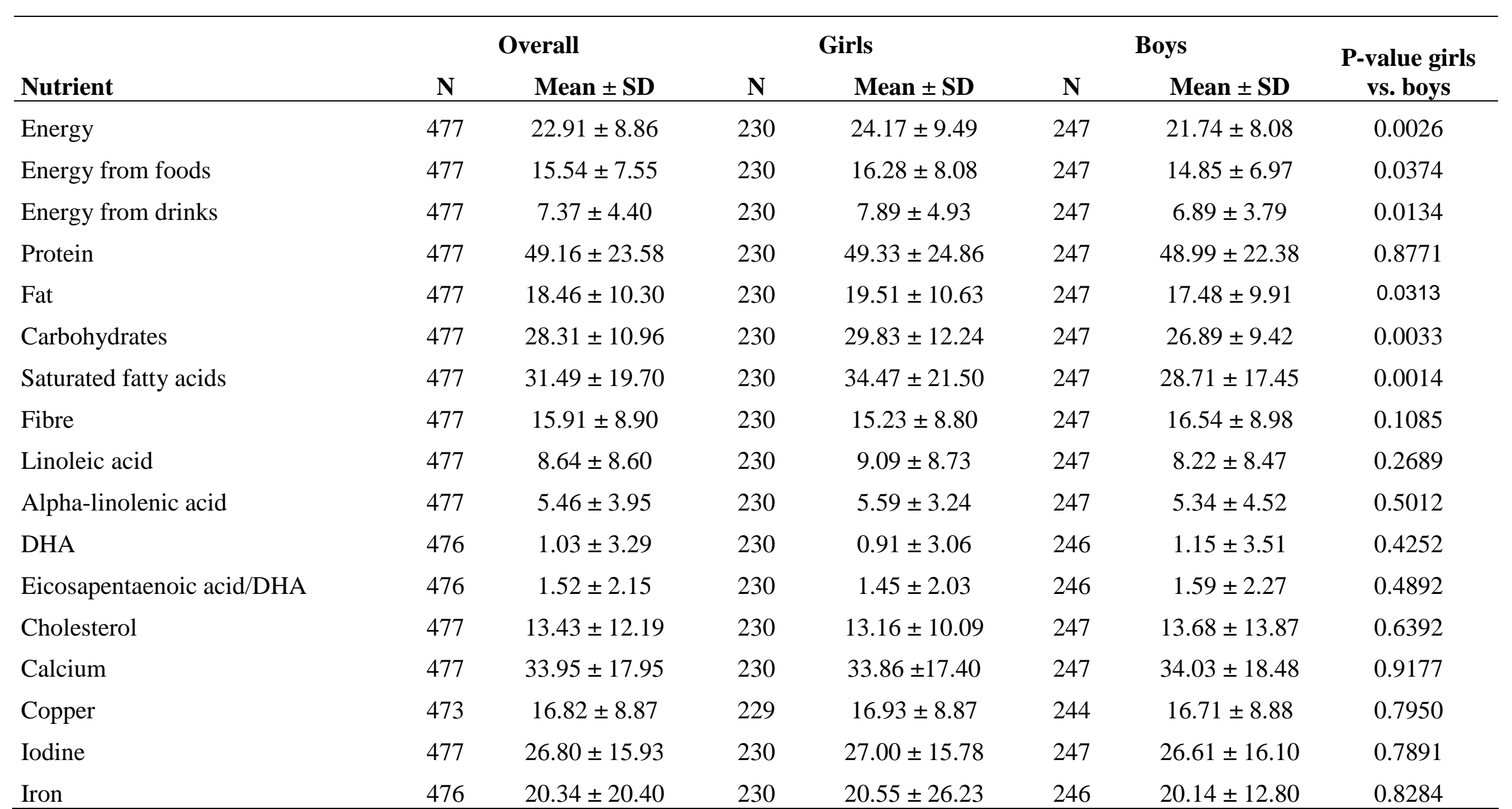




\begin{tabular}{lccccccc}
\hline Magnesium & 477 & $27.14 \pm 12.12$ & 230 & $27.09 \pm 12.34$ & 247 & $27.18 \pm 11.94$ & 0.9361 \\
Phosphorus & 477 & $45.34 \pm 22.76$ & 230 & $44.93 \pm 22.33$ & 247 & $45.73 \pm 23.19$ & 0.7047 \\
Potassium & 477 & $22.57 \pm 9.80$ & 230 & $22.27 \pm 9.87$ & 247 & $22.85 \pm 9.75$ & 0.5210 \\
Selenium & 437 & $7.18 \pm 3.72$ & 216 & $7.09 \pm 3.87$ & 221 & $7.28 \pm 3.58$ & 0.5916 \\
Zinc & 477 & $14.87 \pm 7.79$ & 230 & $14.74 \pm 7.92$ & 247 & $14.99 \pm 7.68$ & 0.7178 \\
Sodium & 477 & $15.35 \pm 9.04$ & 230 & $16.27 \pm 9.86$ & 247 & $14.50 \pm 8.12$ & 0.0322 \\
Retinol & 477 & $20.53 \pm 13.95$ & 230 & $21.48 \pm 13.66$ & 247 & $19.64 \pm 14.18$ & 0.1505 \\
Vitamin C & 461 & $38.32 \pm 35.17$ & 228 & $37.83 \pm 37.55$ & 233 & $38.81 \pm 32.75$ & 0.7639 \\
Vitamin D & 474 & $2.45 \pm 2.70$ & 229 & $2.56 \pm 2.64$ & 245 & $2.34 \pm 2.76$ & 0.3681 \\
Vitamin E & 477 & $12.68 \pm 14.43$ & 230 & $12.27 \pm 14.87$ & 247 & $13.05 \pm 14.02$ & 0.5579 \\
Thiamin B1 & 477 & $38.19 \pm 33.16$ & 230 & $38.47 \pm 41.72$ & 247 & $37.94 \pm 22.52$ & 0.8617 \\
Riboflavin B2 & 476 & $51.70 \pm 33.03$ & 230 & $51.88 \pm 38.11$ & 246 & $51.54 \pm 27.52$ & 0.9091 \\
Niacin B3 & 476 & $25.84 \pm 36.65$ & 230 & $26.45 \pm 46.27$ & 246 & $25.28 \pm 24.55$ & 0.7291 \\
Pantothenic acid B5 & 477 & $44.38 \pm 24.19$ & 230 & $43.03 \pm 24.48$ & 247 & $45.64 \pm 23.90$ & 0.2388 \\
Vitamin B6 & 477 & $38.59 \pm 37.40$ & 230 & $40.01 \pm 47.33$ & 247 & $37.26 \pm 24.84$ & 0.4217 \\
Folate B9 & 477 & $30.43 \pm 22.35$ & 230 & $30.02 \pm 26.98$ & 247 & $30.82 \pm 16.99$ & 0.6941 \\
Vitamin B12 & 477 & $47.67 \pm 32.62$ & 230 & $45.06 \pm 32.39$ & 247 & $50.10 \pm 32.71$ & 0.0919 \\
\hline
\end{tabular}

P-values for girls vs. boys were calculated using a general linear model. SD, standard deviation. 
Supplementary table 3 . Mean nutrient intakes ( \pm standard deviations) by dietary pattern.

\begin{tabular}{|c|c|c|c|c|c|c|c|c|c|}
\hline \multirow{2}{*}{$\begin{array}{l}\mathbf{N} \\
\text { Nutrients }\end{array}$} & \multicolumn{2}{|c|}{$\begin{array}{c}\text { “RTEC + milk } \\
\text { breakfast” }\end{array}$} & \multicolumn{2}{|c|}{$\begin{array}{c}\text { “Sweets } \\
\text { breakfast” }\end{array}$} & \multicolumn{2}{|c|}{$\begin{array}{c}\text { “Traditional } \\
\text { French breakfast” }\end{array}$} & \multicolumn{2}{|c|}{$\begin{array}{c}\text { “Dairy \& Juice } \\
\text { breakfast” }\end{array}$} & \multirow[b]{2}{*}{ Pvalues } \\
\hline & Mean & $S D$ & Mean & $S D$ & Mean & $S D$ & Mean & $S D$ & \\
\hline Protein $(\mathrm{g} / \mathrm{kg})$ & 13.61 & 5.69 & 13.46 & 6.07 & 14.26 & 5.75 & 10.46 & 4.60 & $<.0001$ \\
\hline Protein (\% of energy) & 13.84 & 4.58 & 12.13 & 3.78 & 11.34 & 3.31 & 10.64 & 2.78 & $<.0001$ \\
\hline Fat (g) & 11.02 & 5.69 & 16.60 & 9.43 & 18.60 & 7.68 & 14.49 & 8.31 & $<.0001$ \\
\hline Fat (\%) & 24.24 & 7.55 & 32.26 & 10.03 & 34.01 & 9.84 & 31.04 & 10.36 & $<.0001$ \\
\hline Carbohydrates (g) & 60.32 & 18.49 & 59.25 & 19.51 & 67.82 & 23.11 & 56.82 & 19.73 & $<.0001$ \\
\hline Carbohydrates (\%) & 61.92 & 9.47 & 55.61 & 9.61 & 54.65 & 9.84 & 58.31 & 10.53 & $<.0001$ \\
\hline Starch (g) & 21.94 & 9.90 & 19.21 & 10.35 & 27.79 & 12.32 & 17.84 & 11.79 & $<.0001$ \\
\hline Fibers (g) & 1.93 & 1.11 & 2.25 & 1.21 & 2.79 & 1.37 & 1.75 & 1.17 & 0.0043 \\
\hline Saturated FA (g) & 5.51 & 3.53 & 8.07 & 4.77 & 10.44 & 4.94 & 6.97 & 4.91 & $<.0001$ \\
\hline AGS (\% of energy) & 12.04 & 4.99 & 15.71 & 5.88 & 19.21 & 7.38 & 14.80 & 7.10 & $<.0001$ \\
\hline Linoleic Acid (g) & 0.62 & 0.46 & 0.70 & 0.59 & 0.86 & 1.11 & 0.83 & 0.69 & 0.2864 \\
\hline Alpha-linolenic Acid (g) & 0.08 & 0.05 & 0.13 & 0.10 & 0.13 & 0.06 & 0.12 & 0.08 & $<.0001$ \\
\hline EPA FA (g) & 1.33 & 1.82 & 3.29 & 3.28 & 4.63 & 2.46 & 3.33 & 2.74 & $<.0001$ \\
\hline Omega 3 FA / DHA (g) & 0.69 & 1.61 & 1.68 & 3.06 & 0.95 & 1.92 & 3.49 & 8.91 & $<.0001$ \\
\hline EPA+DHA (g) & 2 & 3.06 & 4.93 & 5.6 & 5.58 & 3.69 & 6.8 & 9.84 & $<.0001$ \\
\hline Monounsaturated FA (g) & 3.19 & 1.74 & 4.82 & 2.74 & 4.91 & 2.29 & 4.24 & 2.77 & $<.0001$ \\
\hline Polyunsaturated FA (g) & 0.90 & 0.55 & 1.16 & 0.77 & 1.41 & 1.55 & 1.24 & 0.97 & 0.2204 \\
\hline Butyric (g) & 0.29 & 0.22 & 0.40 & 0.29 & 0.62 & 0.32 & 0.34 & 0.28 & $<.0001$ \\
\hline Caproic FA (g) & 0.18 & 0.15 & 0.25 & 0.19 & 0.41 & 0.21 & 0.23 & 0.19 & $<.0001$ \\
\hline
\end{tabular}




\begin{tabular}{|c|c|c|c|c|c|c|c|c|c|}
\hline Caprilic FA (g) & 0.11 & 0.09 & 0.13 & 0.10 & 0.24 & 0.12 & 0.11 & 0.10 & $<.0001$ \\
\hline Capric FA (g) & 0.21 & 0.19 & 0.26 & 0.22 & 0.52 & 0.27 & 0.23 & 0.22 & $<.0001$ \\
\hline Lauric FA (g) & 0.33 & 0.23 & 0.41 & 0.32 & 0.55 & 0.28 & 0.34 & 0.26 & 0.0039 \\
\hline Myristic FA (g) & 0.77 & 0.60 & 1.03 & 0.74 & 1.59 & 0.83 & 0.91 & 0.74 & $<.0001$ \\
\hline Palmitic FA (g) & 2.46 & 1.54 & 3.95 & 2.33 & 4.49 & 2.09 & 3.40 & 2.37 & $<.0001$ \\
\hline Stearic FA (g) & 0.75 & 0.47 & 1.11 & 0.66 & 1.39 & 0.68 & 0.93 & 0.64 & $<.0001$ \\
\hline Oleic FA (g) & 2.20 & 1.42 & 3.53 & 2.36 & 3.37 & 1.88 & 3.31 & 2.44 & $<.0001$ \\
\hline Arachidonic FA (g) & 0.00 & 0.00 & 0.00 & 0.01 & 0.00 & 0.00 & 0.00 & 0.01 & 0.0408 \\
\hline Cholesterol (mg) & 26.68 & 18.53 & 40.42 & 29.57 & 46.64 & 24.11 & 36.38 & 45.56 & 0.0186 \\
\hline Calcium (mg) & 373.12 & 160.94 & 339.33 & 184.84 & 361.62 & 171.56 & 251.86 & 105.10 & $<.0001$ \\
\hline Copper (mg) & 0.16 & 0.09 & 0.23 & 0.11 & 0.27 & 0.12 & 0.16 & 0.09 & $<.0001$ \\
\hline Iodine $(\mu \mathrm{g})$ & 38.53 & 19.07 & 35.17 & 20.85 & 37.49 & 20.80 & 22.44 & 15.62 & $<.0001$ \\
\hline Iron (mg) & 2.94 & 1.38 & 1.53 & 0.97 & 1.39 & 0.87 & 1.26 & 0.89 & $<.0001$ \\
\hline Magnesium (mg) & 62.72 & 21.83 & 62.89 & 25.96 & 66.44 & 26.73 & 46.50 & 20.08 & $<.0001$ \\
\hline Phosphorus (mg) & 326.87 & 138.31 & 315.43 & 152.11 & 312.85 & 148.59 & 236.20 & 91.67 & $<.0001$ \\
\hline Selenium ( $\mu \mathrm{g})$ & 3.23 & 1.38 & 3.12 & 1.48 & 3.16 & 1.69 & 1.34 & 1.10 & $<.0001$ \\
\hline Zinc (mg) & 1.54 & 0.65 & 1.53 & 0.75 & 1.61 & 0.81 & 0.97 & 0.46 & $<.0001$ \\
\hline Manganese (mg) & 0.33 & 0.23 & 0.38 & 0.23 & 0.45 & 0.46 & 0.39 & 0.27 & 0.5687 \\
\hline Potassium (mg) & 758.36 & 284.81 & 698.22 & 304.00 & 715.64 & 318.21 & 533.95 & 224.32 & $<.0001$ \\
\hline Sodium (mg) & 363.32 & 170.67 & 340.29 & 188.72 & 480.49 & 182.44 & 310.60 & 199.61 & $<.0001$ \\
\hline Retinol A ( $\mu \mathrm{g}$ ) & 79.01 & 56.48 & 94.73 & 65.31 & 157.48 & 74.18 & 74.32 & 64.02 & $<.0001$ \\
\hline Beta-caroten ( $\mu \mathrm{g})$ & 63.13 & 80.33 & 81.60 & 99.16 & 123.75 & 189.63 & 132.37 & 336.78 & 0.0400 \\
\hline vitamin C (mg) & 48.29 & 32.18 & 34.31 & 29.78 & 30.88 & 32.25 & 33.00 & 30.87 & $<.0001$ \\
\hline vitamin D ( $\mu \mathrm{g})$ & 0.09 & 0.12 & 0.10 & 0.13 & 0.17 & 0.12 & 0.12 & 0.17 & 0.0061 \\
\hline vitamin E (mg) & 1.24 & 1.03 & 1.24 & 0.94 & 1.23 & 2.11 & 1.25 & 1.20 & 0.2455 \\
\hline Vitamin K ( $\mu \mathrm{g})$ & 3.41 & 3.20 & 6.77 & 3.72 & 5.94 & 3.64 & 0.49 & 1.30 & 0.0077 \\
\hline Thiamin B1 (mg) & 0.56 & 0.22 & 0.29 & 0.17 & 0.27 & 0.13 & 0.18 & 0.12 & $<.0001$ \\
\hline Riboflavin B2 (mg) & 0.96 & 0.35 & 0.65 & 0.37 & 0.62 & 0.32 & 0.39 & 0.21 & $<.0001$ \\
\hline Niacin B3 (mg) & 5.48 & 2.76 & 1.75 & 1.72 & 1.50 & 1.20 & 1.24 & 1.23 & $<.0001$ \\
\hline Pantothenic acid B5 (mg) & 2.53 & 0.65 & 1.52 & 0.81 & 1.43 & 0.66 & 0.99 & 0.59 & $<.0001$ \\
\hline
\end{tabular}




\begin{tabular}{|c|c|c|c|c|c|c|c|c|c|}
\hline vitamin B6 (mg) & 0.75 & 0.31 & 0.37 & 0.24 & 0.34 & 0.18 & 0.23 & 0.17 & $<.0001$ \\
\hline Folate B9 ( $\mu \mathrm{g})$ & 95.68 & 38.45 & 64.82 & 34.31 & 47.92 & 31.22 & 62.74 & 33.21 & $<.0001$ \\
\hline vitamin B12 ( $\mu \mathrm{g})$ & 0.89 & 0.37 & 0.81 & 0.54 & 0.62 & 0.38 & 0.56 & 0.45 & $<.0001$ \\
\hline Energy density (Kcal/100g) & 359.21 & 89.19 & 380.32 & 80.57 & 343.96 & 96.84 & 207.23 & 94.15 & $<.0001$ \\
\hline Alcool (g) & 0.00 & 0.00 & 0.00 & 0.00 & 0.00 & 0.00 & 0.00 & 0.00 & \\
\hline Water (g) & 364.59 & 143.40 & 330.03 & 150.73 & 363.37 & 141.52 & 307.30 & 135.66 & 0.0063 \\
\hline
\end{tabular}

${ }^{1} \mathrm{p}$ values referred to a parametric test (i.e. GLM) adjusted for total energy intake. SD, standard deviation 